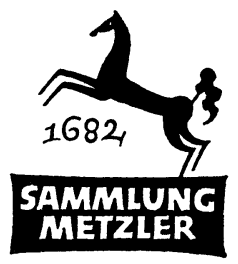

REALIENBÜCHER FÜR GERMANISTEN ABT. G. DOKUMENTATIONEN

(REIHE B: ZU UNRECHT VERGESSENE TEXTE) 


\title{
EDUARD ALLWILLS PAPIERE
}

\author{
FAKSIMILEDRUCK \\ DER ERWEITERTEN FASSUNG VON I $77^{6}$ \\ AUS CHR. M. WIELANDS \\ \TEUTSCHEM MERKUR» \\ MIT EINEM NACHWORT \\ VON \\ HEINZ NICOLAI
}

MCMLXII

J.B. METZLERSCHE VERLAGSBUCHHANDLUNG 
Die Württembergische Landesbibliothek stellte ihr Oringialexemplar des „Teutschen Merkur" dankenswerterweise für die

Reproduktion zur Verfügung.

ISBN 978-3-476-99224-6

ISBN 978-3-476-99223-9 (eBook)

DOI 10.1007/978-3-476-99223-9

(C)

Springer-Verlag GmbH Deutschland 1962

Ursprünglich erschienen bei J. B. Metzlersche Verlagsbuchhandlung und Karl Ernst Poeschel Verlag GmbH in Stuttgart 1962 